OPEN ACCESS

Edited by:

Toni Laaksonen,

University of Turku, Finland

Reviewed by:

Francesc Mestres,

University of Barcelona, Spain

Julien Terraube,

University of the Sunshine Coast,

Australia

*Correspondence:

Kaitlyn M. Gaynor

gaynor@nceas.ucsb.edu

${ }^{\dagger}$ These authors have contributed

equally to this work

Specialty section:

This article was submitted to

Behavioral and Evolutionary Ecology,

a section of the journal

Frontiers in Ecology and Evolution

Received: 10 September 2020

Accepted: 19 February 2021

Published: 11 March 2021

Citation:

Smith JA, Gaynor KM and Suraci JP (2021) Mismatch Between

Risk and Response May Amplify

Lethal and Non-lethal Effects

of Humans on Wild Animal

Populations.

Front. Ecol. Evol. 9:604973.

doi: 10.3389/fevo.2021.604973

\section{Mismatch Between Risk and Response May Amplify Lethal and Non-lethal Effects of Humans on Wild Animal Populations}

\author{
Justine A. Smith ${ }^{1+}$, Kaitlyn M. Gaynor ${ }^{2 \star t}$ and Justin P. Suraci3,4t \\ 'Department of Wildlife, Fish, and Conservation Biology, University of California, Davis, Davis, CA, United States, ${ }^{2}$ National \\ Center for Ecological Analysis and Synthesis, University of California, Santa Barbara, Santa Barbara, CA, United States, \\ ${ }^{3}$ Center for Integrated Spatial Research, Environmental Studies Department, University of California, Santa Cruz, Santa Cruz, \\ CA, United States, ${ }^{4}$ Conservation Science Partners, Inc., Truckee, CA, United States
}

Human activity has rapidly transformed the planet, leading to declines of animal populations around the world through a range of direct and indirect pathways. Humans have strong numerical effects on wild animal populations, as highly efficient hunters and through unintentional impacts of human activity and development. Human disturbance also induces costly non-lethal effects by changing the behavior of risk-averse animals. Here, we suggest that the unique strength of these lethal and non-lethal effects is amplified by mismatches between the nature of risk associated with anthropogenic stimuli and the corresponding response by wild animals. We discuss the unique characteristics of cues associated with anthropogenic stimuli in the context of animal ecology and evolutionary history to explore why and when animals fail to appropriately (a) detect, (b) assess, and (c) respond to both benign and lethal stimuli. We then explore the costs of over-response to a benign stimulus (Type I error) and underresponse to a lethal stimulus (Type II error), which can scale up to affect individual fitness and ultimately drive population dynamics and shape ecological interactions. Finally, we highlight avenues for future research and discuss conservation measures that can better align animal perception and response with risk to mitigate unintended consequences of human disturbance.

Keywords: anthropogenic disturbance, antipredator behavior, conservation behavior, harvest, human-induced fear, predation risk, recreation, risk effects

\section{INTRODUCTION}

Humans often fill an outsized role in ecological communities, exerting strong lethal and non-lethal effects on animal populations. People around the world rely on wild animal products (Ripple et al., 2016) and harvest rates by humans far exceed predation rates of wild predators globally (Darimont et al., 2015). Furthermore, many aspects of the built environment (e.g., roads, buildings, and energy infrastructure) or introduced materials (e.g., poisons and plastics) pose an incidental lethal threat to wild animals (Horn et al., 2008; Smallwood, 2013; Loss et al., 2015; Mccardle and Fontenot, 2016). Even where human activity is non-lethal, the impacts of human disturbance can be analogous to the risk effects of predation (Frid and Dill, 2002). Disturbance can induce costly antipredator 
behaviors (Smith et al., 2017; Suraci et al., 2019) that are known to compromise individual fitness and influence population dynamics in other predator-prey systems, with implications for entire ecosystems (Peckarsky et al., 1993; Peacor et al., 2011; Cherry et al., 2016). Many recent studies have demonstrated that animals perceive and respond to risk associated with human activity and infrastructure, even in the absence of a true threat (Larson et al., 2016; Gaynor et al., 2018). As the human footprint expands across the planet, both the lethal and non-lethal impacts of human disturbance have important implications for global biodiversity conservation.

Human activity is driving global declines of wild animal populations (Dirzo et al., 2014), in part due to the inability of animals to effectively respond to pervasive, rapid environmental change (Sih, 2013). Although humans have co-evolved and interacted with many species for millennia (Bird and Nimmo, 2018) and many animals do effectively navigate the risks posed by people (Oriol-Cotterill et al., 2015; Thurfjell et al., 2017; Ditmer et al., 2018), modern human cues can be especially novel, unreliable, and/or pervasive, leading to mismatches between exhibited behaviors and optimal behavioral responses (Trimmer et al., 2017a). Anti-predator behavior and other risk mitigation strategies, which reduce an individual animal's risk of mortality from predation or other environmental threats, can have high-stakes fitness consequences if over- or under-employed. Furthermore, human-induced changes in animal behavior can potentially alter ecosystems through many pathways, though many have yet to be documented and it remains an important area for future research (Wilson et al., 2020). Risk-response mismatch in human-modified environments is therefore of particular conservation concern (Saul and Jeschke, 2015; Owen et al., 2017; Guiden et al., 2019). In the modern world, many animal populations are exposed to diverse anthropogenic threats while also inhabiting environments saturated with benign anthropogenic stimuli. A failure to respond appropriately to both benign and lethal anthropogenic stimuli can cause or exacerbate population declines.

We contend that the mismatches between risk and response can amplify the unique strength of anthropogenic lethal and non-lethal effects on animal populations (Figure 1). A Type I error, in which animals perceive risk from a benign stimulus, can lead to an over-response that amplifies the non-lethal effects of human disturbance. A Type II error, in which animals fail to perceive or respond appropriately to risk from a stimulus that poses a threat, can lead to an under-response that accentuates the lethal effects of human disturbance. Here we discuss how the unique characteristics of anthropogenic cues can drive mismatches between the actual level of risk and animal response, with the potential for population-level consequences. We then argue that, given the pervasiveness of human activity, such mismatches between actual and perceived anthropogenic risk are widespread and may contribute to species declines globally, exacerbating the myriad impacts of humans on wild animal populations. Finally, we suggest avenues for future research to better integrate behavioral risk mismatches into conservation and management strategies.

\section{THE UNIQUE NATURE OF ANTHROPOGENIC RISK CUES}

Over evolutionary and ecological time scales, animals develop a set of decision rules for distinguishing between safe and risky situations based on sensory cues (Blumstein and Bouskila, 1996; Welton et al., 2003). When faced with novel anthropogenic stimuli, animals are sometimes able to rely on these decision rules, accurately assess the level of threat, and respond accordingly for an optimal fitness outcome (Sih, 2013). When sensory cues are reliable, animals may also be able to draw on past experience and rapidly develop appropriate responses to changes in their environment (e.g., habituating to a new but benign stimulus; Trimmer et al., 2017b). However, as outlined below, such decision rules and opportunities for learning may break down when animals are faced with the novelty, diversity, and unreliability of anthropogenic stimuli and associated sensory cues, or with the emergence of confounding ecological traps, all of which may limit an animal's ability to appropriately detect, assess, or respond to human activity (Sih et al., 2011; Sih, 2013; Dominoni et al., 2020; Figure 1). We propose three alternative hypotheses that may explain the mismatch between risk and response to anthropogenic stimuli in a given situation (Table 1):

1. Detection Mismatch Hypothesis: Lethal anthropogenic stimuli produce cues that are not detectable by the animal at the relevant scale of the threat, leading to Type II error.

2. Assessment Mismatch Hypothesis: Non-lethal or lethal anthropogenic stimuli produce detectable cues, but the associated level of risk is not accurately assessed by the animal, leading to Type I or II error.

3. Response Mismatch Hypothesis: Lethal anthropogenic stimuli produce cues that are accurately assessed as risky, but the animal's response is inappropriate or inadequate to reduce the associated threat, leading to Type II error.

Observation of Type I errors (over-response) provide support for the Assessment Mismatch Hypothesis, largely occurring as a result of animals incorrectly assessing a benign anthropogenic stimulus as threatening due to novelty or similarity to predator cues (Frid and Dill, 2002). Observation of Type II errors (underresponse) may support any of the above hypotheses (Detection, Assessment, or Response Mismatch) and occur when animals are presented with novel threats to which their sensory capabilities or behavioral decision rules are not well adapted. Each hypothesis also predicts different lethal or non-lethal outcomes. Detection and response mismatch can result in injury or death due to under-response to lethal stimuli, while assessment mismatch may result in either sub-lethal fitness costs (in the case of over-responding to benign stimuli) or death (following underresponse to lethal stimuli). Quantifying support for our proposed hypotheses can aid in determining the presence, mechanism, and outcome of risk-response mismatches in animal populations. Below, we discuss how specific characteristics of human cues may cause detection, assessment, and response mismatches in animal populations. 


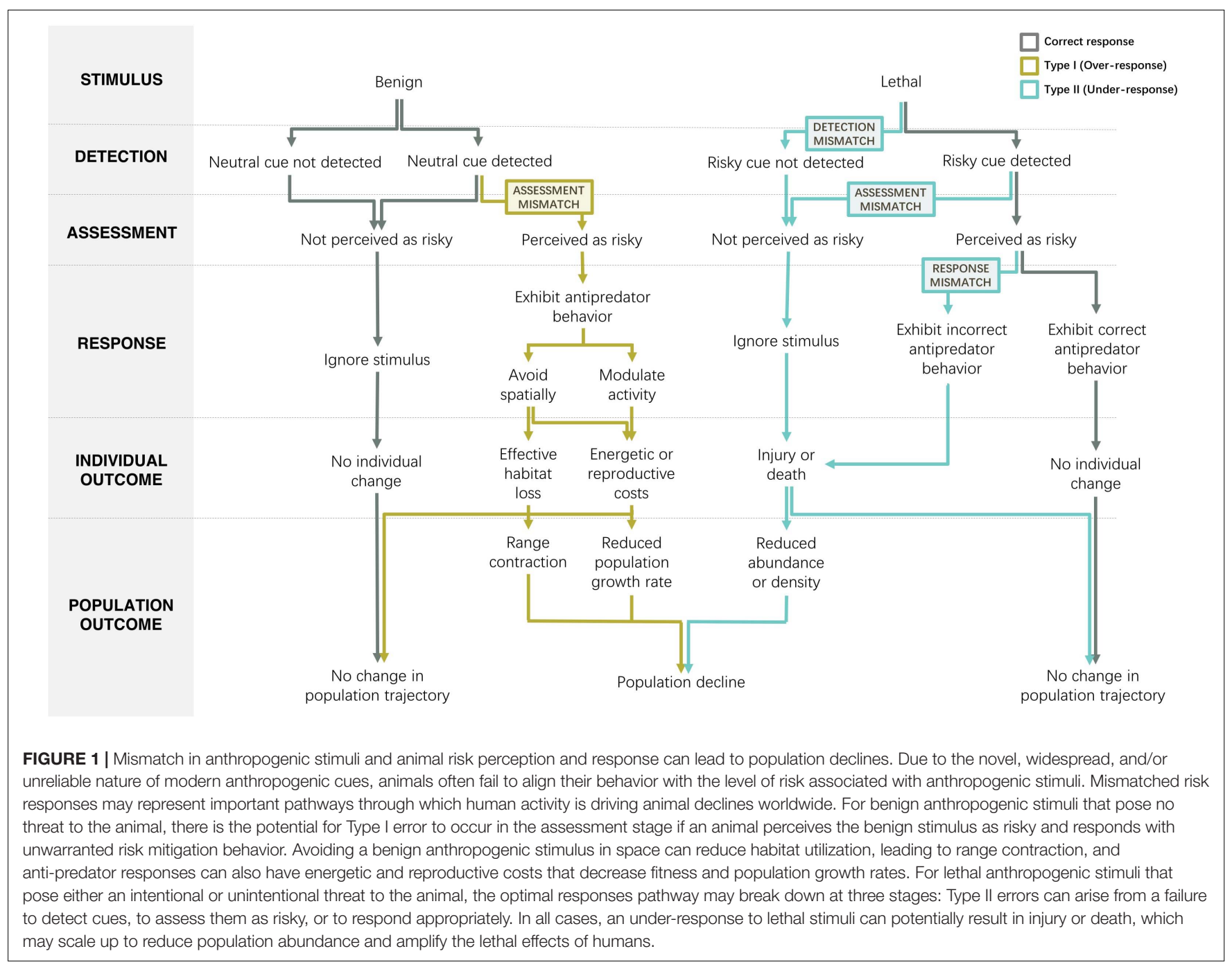

\section{Detection Mismatch Hypothesis: Inadequate Detection of Risky Anthropogenic Cues (Type II Error) Inability to Detect Sensory Stimuli}

Some anthropogenic threats may not be detectable due to mismatch between all associated cues and the sensory modalities of the animal (Fisher et al., 2006; Serieys et al., 2015), leading to an unavoidable under-response to risk. This failure to detect risk is responsible for birds colliding with windows, fish consuming toxic plastics, and a range of other unintended phenomena (Loss et al., 2012). In other cases, anthropogenic threats are designed to be undetectable: advances in hunting technology have not only made humans dramatically more lethal than non-human predators (Darimont et al., 2015), but in many cases also serve to minimize the prey's ability to detect the hunter. For instance, while fished populations can quickly learn to avoid spear fishers, which generate many of the cues associated with non-human predators (Tran et al., 2016), large-scale fishing is done remotely using gear like monofilament lines and nets that are effectively invisible to fish (Meekan et al., 2018).

\section{Cue and Risk Separated in Time and Space}

Some anthropogenic threats may generate perceptible cues that are disconnected from the threat itself in space and/or time, disrupting an animal's ability to detect the relevant risk cues. For instance, retaliatory killing in response to livestock predation or crop raiding is a major threat to many wildlife populations, but the stimuli that trigger these behaviors, i.e., livestock pens or agricultural fields, may be dissociated from cues of human risk if depredating animals are killed in another place or time (Thapa, 2015; Loveridge et al., 2017). Similarly, animals that are hunted using long range rifles from hundreds of meters away may exhibit less change in habitat use than those exposed to bowhunters who must hunt at much closer range (Thurfjell et al., 2017).

\section{Assessment Mismatch Hypothesis: Incorrect Assessment of Risky or Neutral Anthropogenic Cues (Type I or II Error) Unreliability of Cues}

Many anthropogenic cues are only associated with a threat in certain contexts, making them unreliable indicators of 
TABLE 1 | Predicted responses to anthropogenic stimuli associated with three alternative hypotheses for risk-response mismatch.

\begin{tabular}{|c|c|c|c|}
\hline Hypothesis & Conditions leading to mismatch & Observable outcomes & Examples \\
\hline Detection mismatch & $\begin{array}{l}\text { - Limited sensory capacity of } \\
\text { organism (morphological or } \\
\text { physiological constraints) } \\
\text { - Cue is decoupled from threat in } \\
\text { space or time }\end{array}$ & $\begin{array}{l}\text { Type Il error } \\
\text { - No discernable response to stimulus }\end{array}$ & $\begin{array}{l}\text { - Animal collides with window glass (Loss } \\
\text { et al., 2012) } \\
\text { - Animal consumes poisons/toxins } \\
\text { (Serieys et al., 2015) } \\
\text { - Animal does not detect boat cue } \\
\text { decoupled in space from fishing } \\
\text { equipment (Meekan et al., 2018) } \\
\text { - Animal does not substantially avoid or } \\
\text { anticipate retaliatory killing (Loveridge } \\
\text { et al., 2017) }\end{array}$ \\
\hline Assessment mismatch & $\begin{array}{l}\text { - Unreliability of cue; may be } \\
\text { associated with both lethal and } \\
\text { non-lethal human activity } \\
\text { - Novelty of cue; does not resemble } \\
\text { risk cues encountered in evolutionary } \\
\text { history } \\
\text { - Cue is also associated with benefit }\end{array}$ & $\begin{array}{l}\text { Type I error } \\
\text { - Avoidance of stimulus in time or } \\
\text { space } \\
\text { - Changes in activity budget, } \\
\text { movement, foraging in proximity to } \\
\text { stimulus } \\
\text { Type Il error } \\
\text { - Animal may examine or } \\
\text { acknowledge stimulus, but exhibits } \\
\text { no risk-avoidance response (and } \\
\text { may even show attraction to it) }\end{array}$ & $\begin{array}{l}\text { Type I error } \\
\text { - Animal avoids non-lethal human } \\
\text { infrastructure (Sawyer et al., 2017) } \\
\text { - Animal avoids habitats with greater } \\
\text { non-lethal recreation (Rösner et al., } \\
\text { 2014) } \\
\text { Type II error } \\
\text { - Animal does not avoid hunters or fishing } \\
\text { gear (Thouless et al., 1991; Meekan } \\
\text { et al., 2018) } \\
\text { - Animal is attracted to resource subsidies } \\
\text { increases vulnerability to harvest or } \\
\text { accidental death (Johnson et al., 2020) } \\
\text { - Toxins present olfactory trap for a } \\
\text { foraging animal (Savoca et al., 2017) }\end{array}$ \\
\hline Response mismatch & $\begin{array}{l}\text { - Novelty of cue; does not resemble } \\
\text { risk cues encountered in evolutionary } \\
\text { history } \\
\text { - Animal exhibits generalized response } \\
\text { to all risk cues } \\
\text { - Animal has morphological or } \\
\text { physiological constraints that limit } \\
\text { degree of response }\end{array}$ & $\begin{array}{l}\text { Type Il error } \\
\text { - Animal exhibits inappropriate } \\
\text { response that does not reduce risk } \\
\text { - Animal exhibits response of } \\
\text { inadequate magnitude }\end{array}$ & $\begin{array}{l}\text { Type Il error } \\
\text { - Animal freezes in front of vehicle, leading } \\
\text { to collision (Mazerolle et al., 2005) } \\
\text { - Animal flees vehicle at inadequate speed } \\
\text { (Bernhardt et al., 2010) } \\
\text { - Animal flees harvest equipment to } \\
\text { inadequate distance (Suuronen et al., } \\
\text { 1997) }\end{array}$ \\
\hline
\end{tabular}

risk. This unreliability makes it difficult for animals to learn how to appropriately assess these cues, or to correctly apply evolved decision rules. Although some species do appear able to differentiate between lethal and non-lethal human activity (McComb et al., 2014; Tran et al., 2016), cue overlap between risky and non-risky humans-for example, the sound of a human voice-may make this distinction difficult for many species and populations, particularly in places where hunting and non-lethal recreation co-occur (Kays et al., 2017). Generalized responses will therefore be associated with an "incorrect" risk perception some of the time: if an animal's generalized response to humans is to avoid or flee, there will be more Type I error (over-response) as a result of benign human activities, but if an animal's generalized response is to ignore people, there will be more Type II error (under-response) when exposed to intentional take. The degree to which these generalized responses scale up to have a net impact on populations will depend on the relative frequency of lethal and benign stimuli in the environment.

Habituation to neutral cues or sensitization to risky cues can potentially reduce erroneous responses to human activity as animals learn from previous experiences with humans. However, when cues are unreliable, habituation can lead to more Type II error (under-response) and sensitization to more Type I error (over-response), furthering the mismatch between underlying risk and response. For instance, DeVault et al. (2016) showed that rock doves (Columba livia) that have habituated to the cues of passing vehicles (a benign stimulus when animals are not directly on the road) failed to escape effectively in simulated collision scenarios, suggesting that the subtle difference in context between lethal and benign vehicles (i.e., animal on or off the road) may be difficult for some species to distinguish.

\section{Novelty of Risks and Anthropogenic Disturbances}

In addition to being unreliable signals of risk, anthropogenic stimuli are often novel. Even in animal populations that have been long exposed to human activity, the continuous introduction of new technologies and features of the built environment generates cues that have no evolutionary analog (Darimont et al., 2015; Nyhus, 2016). As is the case with invasive predators (Sih et al., 2010; Carthey and Blumstein, 2017), the similarity of novel anthropogenic cues to predator cues and the neophobia of the animal should govern the nature of an animal's response to the novel cue and the most likely form of error. Where novel cues bear little resemblance to familiar stimuli, the likelihood than an animal will assess these cues as risky and respond accordingly may depend on the amount and diversity of predation risk the population has experienced in the past (Cox and Lima, 2006; Ferrari et al., 2015; Ehlman et al., 2019). 
Additionally, the risk disturbance hypothesis (Lima and Bednekoff, 1999; Frid and Dill, 2002) suggests that many features of humans and our associated technologies and infrastructureloud noises, large body size, rapidly approaching objects-do overlap with those of predators and thus elicit responses to generalized predation risk, even where activity is benign (Sih et al., 2010; Trimmer et al., 2017b). However, an evolved fear response to large or fast objects may not adequately prepare animals to appropriately assess deadly anthropogenic cues that are not associated with an approaching human form. Furthermore, in populations that have not experienced predation in their recent evolutionary history, animals may not exhibit any generalized risk response at all, as suggested by the "island tameness hypothesis" (Cooper et al., 2014). In these cases, both ontogenetic and evolutionary naiveté to risky cues contribute to Type II error (Cox and Lima, 2006). Additionally, because humans and associated threats are often highly lethal (Darimont et al., 2015), there may be fewer failed "predation attempts" by hunters, vehicles, or other anthropogenic infrastructure, from which an animal might otherwise learn to associate these novel cues with risk.

\section{Ecological and Evolutionary Traps}

Not only do animals often fail to accurately associate risk with anthropogenic stimuli; they may also assign perceived benefit to stimuli that are, in fact, risky (e.g., Johnson et al., 2020). Snakes are attracted to the heat of asphalt on roadways, putting them at risk for vehicle collisions (Mccardle and Fontenot, 2016). In other cases, hunters or fishers will intentionally pair risky stimuli like traps and nets with attractive cues like baits (Carroll, 2007; Mandelman et al., 2008). These maladaptive responses to socalled ecological or evolutionary traps can increase the likelihood of a Type II error, or under-response to risk, due to incorrect assessment of risky cues or miscalibration of resource-safety trade-offs (Robertson et al., 2013).

\section{Response Mismatch Hypothesis: Inappropriate Response to Risky Anthropogenic Cues (Type II Error)}

Even in the case of accurate risk detection and assessment, animals may not respond appropriately to anthropogenic threats. In certain situations, an animal's generalized anti-predator response may not reduce anthropogenic risk because the stimulus is novel in the context of a species' evolutionary history. The "deer in headlights" is a clear example of a counterproductive response: by freezing to avoid "predator" detection in response to an oncoming vehicle, animals actually increase their risk of collision (Mazerolle et al., 2005). In other cases, an animal's response may be appropriate but inadequate (Bernhardt et al., 2010), given that the lethality of anthropogenic threats often necessitates extreme responses to risky cues to avoid death. Animals may be limited both behaviorally and physiologically in their responses to risks; for example, the generalized response of many birds to volant predators is to dodge the predator once it is at close range a response that is ineffective with airplanes (Bernhardt et al., 2010) and vehicles (DeVault et al., 2015). Response mismatches can also occur when humans are intentionally lethal, such as when game species are chased into trees using hound dogs (Bryce et al., 2017) where they can be shot by hunters, or when narwhals exhibit maladaptive physiological responses from net entanglement (Williams et al., 2017).

\section{INDIVIDUAL- AND POPULATION-LEVEL COSTS OF MISMATCH}

The overexploitation of wild animals by humans and other forms of incidental killing have clear numerical top-down effects on animal populations, but the behaviorally mediated effects of lethal and non-lethal human activity have received less attention. These behavioral mechanisms and resulting population-level consequences are difficult to measure, but may represent important pathways through which human activity contributes to population declines. Inappropriate behavioral strategies to confront anthropogenic risks can be key impediments to the long-term viability of populations. The incorrect detection, assessment, and response to risky cues can lead to population declines either directly through death (Type II error) or indirectly through stress effects or functional habitat loss (Type I error; Figure 1). In order to predict and mitigate population-level consequences and subsequent species declines from anthropogenic stimuli, it is necessary to test: (1) if mismatch is occurring; (2) at which stage mismatch occurs (detection, assessment, or response); and (3) why the mismatch occurs.

\section{Costs of Type I Errors}

The Assessment Mismatch Hypothesis predicts that the unreliability or novelty of human cues can result in a generalized risk response to benign anthropogenic stimuli. Signal detection and error management theory show that, in general, animals tend to overrespond to potentially risky stimuli (Johnson et al., 2013; Orrock et al., 2015), given that the possibly lethal cost of Type II error (under-response) is greater than the energetic and opportunity costs of Type I error (over-response; Bouskila and Blumstein, 1992). However, given the many neutral anthropogenic cues that animals may associate with some degree of risk, this "erring on the side of caution" can be costly (Fardell et al., 2020). Mismatch can thus amplify the risk or non-lethal effects of anthropogenic stimuli, which can have a far greater cost than those from predation given the widespread nature of human disturbance (Venter et al., 2016) and the maladaptive nature of Type I errors (Carrete and Tella, 2013; Møller et al., 2014). For populations prone to neophobia or generalized risk responses, the costs of responding to pervasive and continuously changing human stimuli may quickly reach unsustainable levels.

In response to perceived risk from people, animals may avoid areas of higher human use (Rösner et al., 2014; Patten and Burger, 2018; Wisdom et al., 2018) or times of day when people are most active (Gaynor et al., 2018; Nickel et al., 2020), preventing them from accessing resources (Kerley et al., 2002; Smith et al., 2015). While opportunity costs on individual fitness can be difficult to quantify, avoidance of human activity has been linked to range contraction and reduced habitat availability 
for several populations (Merenlender et al., 2009; Rogala et al., 2011; Heinemeyer et al., 2019). This functional habitat loss, in addition to physical habitat loss, is rarely quantified when identifying available habitat for populations (Northrup et al., 2015). Avoidance of anthropogenic structures dramatically reduces the habitat and resources available to animals through the act of over-response to human activity (Lesmerises et al., 2018; Dwinnell et al., 2019).

Over-response to anthropogenic stimuli can also have direct energetic, reproductive, or physiological costs for wild animals. In the presence of humans, increased vigilance and reduced feeding time can lead to lower energetic intake (Stockwell et al., 1991; Fernández-Juricic et al., 2003; Blumstein et al., 2005; Smith et al., 2015, 2017). Energy expenditure can increase as a result of flight in the presence of people or increased movement in areas with higher human disturbance (Bradshaw et al., 1998; Stankowich, 2008). A heightened perception of risk in response to people can also increase stress levels (Creel et al., 2002; Müllner et al., 2004; Amo and López, 2006; Zbyryt et al., 2017). Furthermore, human disturbance has been found to interfere with reproductive activities: for example, ecotourism has been shown to negatively influence ruddy turnstone (Arenaria interpres) nesting success (Beale and Monaghan, 2004), hoatzin (Opisthocomus hoazin) chick survival (Müllner et al., 2004), yellow-eyed penguin (Megadyptes antipodes) fledgling weight (McClung et al., 2004), and California sea lion (Zalophus californianus) population growth rates (French et al., 2011).

\section{Costs of Type II Errors}

The costs of a Type II error, in which an animal perceives a risky stimulus as safe, are more straightforward to quantify, as underresponding to lethal stimuli often results in death or injury. These lethal impacts of humans have been well-documented (Darimont et al., 2015). While the magnitude and effectiveness of human hunting can be largely attributed to technology and demand, it is also likely that the numerical effects of hunting are amplified by the failure of animals to accurately associate cues with risk for the reasons discussed above. Animals are easier to encounter, detect, and capture if they do not associate risk with stimuli such as vehicles, boats, radar, scopes, guns, or traps, or with humans themselves (e.g., Donadio and Buskirk, 2006). For example, during the late Pleistocene extinctions in the Americas, naïve prey under-responded to human hunters, which magnified the numerical effect of harvest (Cox and Lima, 2006). Novelty, unreliability, and spatiotemporal disconnect continue to result in high rates of human caused mortality (both intentional and unintentional) and species declines. Associated under-responses to risk contributed to the recent extinction of a number of species, including the Saudi gazelle (Gazella saudiya; Thouless et al., 1991) and Caribbean monk seal (Neomonachus tropicalis; McClenachan and Cooper, 2008). Many of the unintentional causes of animal mortality are also exacerbated by the failure of individual animals to associate them with risk and avoid them accordingly, including roads, infrastructure like glass windows and powerlines, pollutants and poisons, and accidental killing (e.g., nest destruction) through agriculture and forestry (Mazerolle et al., 2005; Bernhardt et al., 2010). Ultimately, the costs of individual Type II errors likely contribute to source-sink dynamics, population declines, and local extinctions. Because Type II errors can occur at multiple stages, testing of the Detection, Assessment, and Response Mismatch Hypotheses can elucidate the mechanism of risk-response mismatch in vulnerable populations.

\section{CONSERVATION APPROACHES TO REALIGN STIMULI AND RISK PERCEPTION}

While studies directly linking over- or under-response to anthropogenic stimuli with population declines remain rare, the costs associated with inappropriate responses to human risk suggest that these mechanisms may constitute major threats to some wildlife species (Figure 2), contributing to heightened extinction risk. The expansion of key research areas would aid in our ability to predict where and when behavioral mismatches are likely to be of conservation concern and suggest potential mitigation strategies to alleviate the impacts of inappropriate responses to anthropogenic stimuli.

For Type I errors, the potential for habituation to neutral human cues is a primary factor determining whether shortterm, sublethal costs of responding to humans (e.g., increased vigilance and changes in habitat use) will translate into longterm, population-level impacts. Some wildlife populations have been suggested to habituate relatively quickly to anthropogenic disturbances initially perceived as threatening (e.g., non-lethal recreation and ecotourism; Bateman and Fleming, 2017). Individuals in these populations are able to learn, through repeated exposures, to dissociate human cues from risk, thus reversing the risk assessment mismatch and reducing or avoiding downstream costs (Figure 1). In recreational areas, habituation can be facilitated by creating fencing or buffers that make human activity appear less threatening and more predictable (Weston et al., 2012). In other cases, responses to disturbance appear to be highly persistent. For instance, mule deer (Odocoileus hemionus) avoidance of resource extraction infrastructure has been shown to persist for at least 15 years and across generations, potentially contributing to population declines (Sawyer et al., 2017). The speed with which habituation occurs, or whether it occurs at all, will determine the magnitude of any long-term impacts on a population exposed to a benign anthropogenic stimulus. However, the drivers of variation in the likelihood and extent of habituation to human stimuli are not well understood and are likely a function of both stimulus type and ecological context (e.g., similarity between anthropogenic cues and those of actual predators).

Additionally, even habituation (e.g., reduced populationaverage response to human disturbance with time) may not imply an absence of Type I error costs at the individual level (Bejder et al., 2009; Blumstein, 2016). Reduced responsiveness to human disturbance at the population level may be the result of a "personality filter" (Wat et al., 2020) wherein less tolerant individuals avoid the disturbance source (thus experiencing effective habitat loss) while a subset of more human-tolerant 


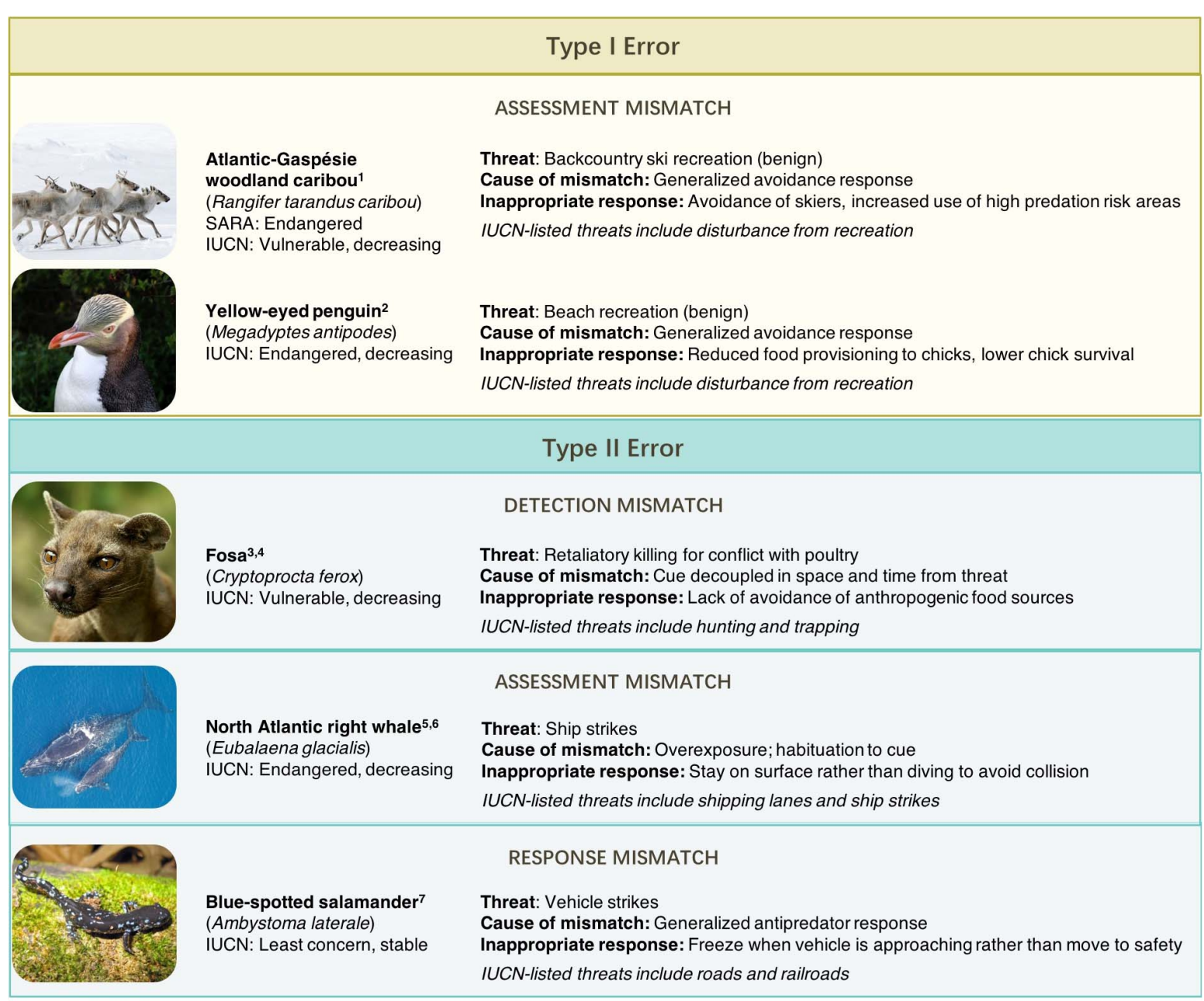

1. Lesmerises et al. (2018). 2. McClung et al. (2004). 3. Kotschwar et al. (2015). 4. Merson et al. (2019). 5. Nowacek et al. (2004). 6. Parks et al. (2011). 7. Mazerolle et al. (2005).

FIGURE 2 | Conservation implications of risk-response mismatch. Examples of species whose declines may be accelerated as a result of Type I and Type II errors in anthropogenic risk detection, assessment, and response. Global species status shown from the International Union of Concerned Scientists (IUCN); Canadian population status shown for Atlantic-Gaspésie woodland caribou from the Species at Risk Act (SARA).

individuals continues to use disturbed areas (Samia et al., 2015). Animals that fail to avoid human disturbance may also be restricted in their ability to leave disturbed areas due to a lack of suitable habitat elsewhere (Blumstein, 2016), despite experiencing persistent sub-lethal costs from fear of humans. Human disturbance can act as a selection pressure, shifting the population toward bolder individuals that are more tolerant of benign human stimuli (Arroyo et al., 2017). However, increased boldness may have other indirect costs such as decreased breeding success (through reduced parental care) and increased susceptibility to predation from non-human predators (Geffroy et al., 2015).

Mitigation of the conditions that promote Type I and II errors can be achieved when mechanisms of risk and response mismatches are better understood (Figure 3). Novel cues, such as those produced by many human activities, may either elicit a fear response upon first encounter (i.e., neophobia; Crane et al., 2019) or may require learning to be recognized as risky (Griffin, 2004).
Theory suggests that the likelihood of a species responding to a novel predator cue will increase with background levels of risk in the animal's environment and the diversity of predators with which the species has experience (Blumstein, 2006; Ehlman et al., 2019). Empirical work examining the generality of these predictions for wildlife responses to human stimuli (e.g., whether greater predator diversity leads to a higher probability of Type I responses to neutral human cues) will improve our ability to anticipate where deleterious behavioral responses to benign human stimuli are likely to occur. In other cases, a lack of overlap between the risky cues of lethal human stimuli and those of predators with which a species is familiar may necessitate learning to avoid Type II misclassification of such cues as neutral. In an analogous scenario - the exposure of naïve prey to a novel predator through invasion or reintroduction - predator training programs have been used to help prey learn an appropriate fear response to the novel predator by pairing predator cues with aversive stimuli (e.g., Van Heezik et al., 1999). Such programs 


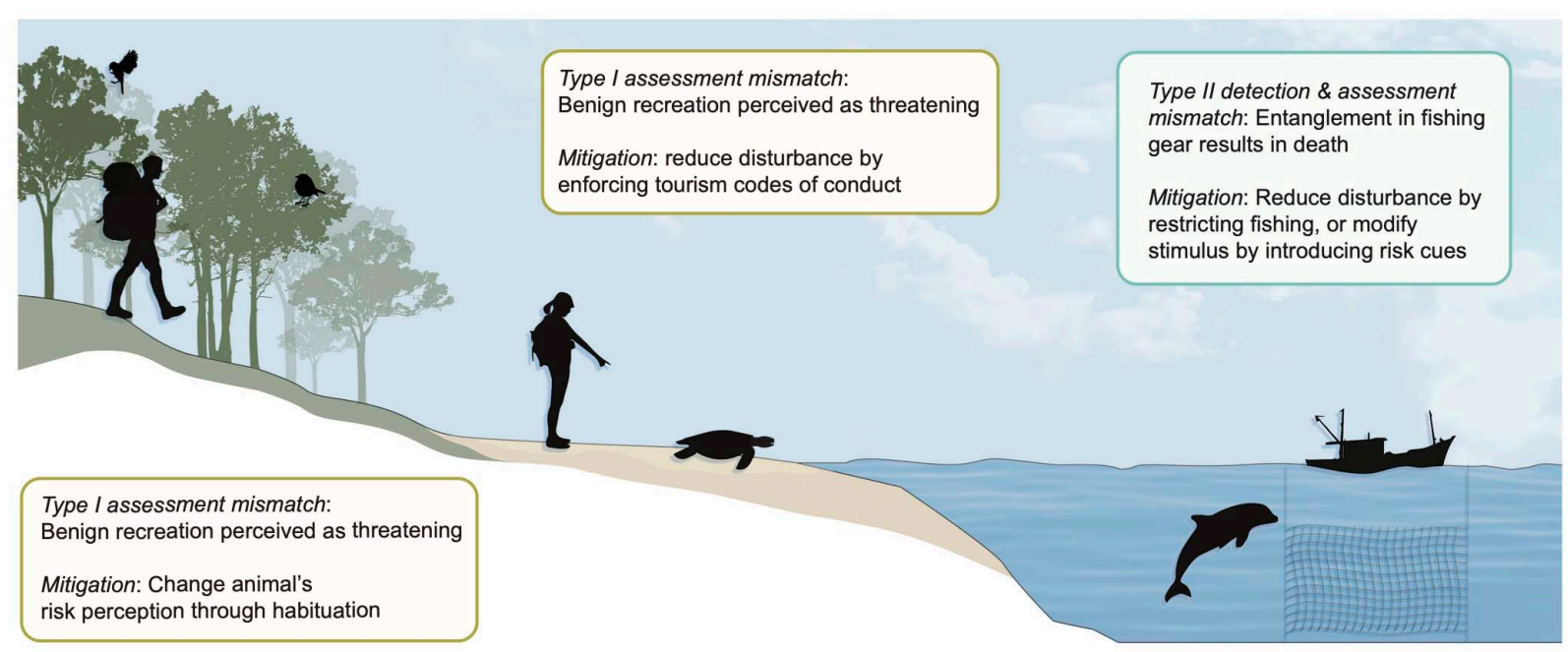

FIGURE 3 | Examples of mitigation measures for reducing risk-response mismatch in wild animals. Managers can employ several strategies to mitigate costly consequences of mismatch between anthropogenic risk and response in wild animal populations. The design of interventions should be informed by the type of mismatch (detection, assessment, or response, and Type I or II error), the nature of the anthropogenic stimulus, and the behavioral plasticity of the target species. One mitigation approach for Type II assessment errors is to gradually habituate animals to a benign stimulus, such as non-consumptive outdoor recreationists. Another strategy, which can be employed for all types of mismatch, is to reduce animal encounters with the disturbance stimulus by minimizing the disturbance (e.g., mitigating ecotourism-induced disturbances). The stimulus itself can also be modified to be more detectable (for Type II detection error) or more fear-inducing (for Type I or II assessment error) - these approaches can be employed to minimize fisheries bycatch.

have been met with mixed success (Blumstein et al., 2019), but may be valuable for efforts to reintroduce species susceptible to novel anthropogenic threats. For instance, using aversive conditioning to train "problematic" carnivores or reintroduced herbivores to associate humans and their settlements with risk may aid in reducing human-wildlife conflict and retaliatory killings (Petracca et al., 2019; Young et al., 2019). This approach may be particularly effective in species where fear responses are culturally transmitted from older to younger individuals (McComb et al., 2014).

Fear conditioning to human stimuli represents one example of a broader set of potential conservation strategies for mitigating the impacts of behavioral mismatch, which can be designed to realign risk perception with the actual level of threat posed by human stimuli. Efforts to match risk and response can either increase the risk associated with lethal stimuli or decrease perceived risk of benign stimuli. For animals in which detection mismatch is the source of increased risk, conservation interventions can focus on introducing perceptible cues (e.g., bird-safe glass) or removing the threat (e.g., proper disposal of plastics). When Type I assessment mismatch occurs, repeated exposure of young individuals to non-threatening human encounters can be employed to intentionally habituate wildlife to benign recreational activity (Blumstein, 2016). Type II assessment mismatches can be managed to increase animal responses to risky human cues; recent proposals have called for amplifying predation risk associated with human hunters by increasing hunter cue intensity, which may help to reduce human-wildlife conflict (Cromsigt et al., 2013). Moving forward, we suggest that the potential for mismatched behavioral responses to human cues must be a key consideration when designing species recovery and reintroduction programs or when opening otherwise low disturbance areas to increased recreational or development activity. Indeed, some conservation and management programs have already begun to incorporate information on potential mismatches between anthropogenic risk and animal responses, confirming the importance of such approaches for effective wildlife management. Here we highlight three conservation scenarios in which managing for potential risk-responses mismatches shows particular promise (Figure 3).

\section{Mitigating Non-lethal Impacts of Recreation Through Habituation}

Outdoor recreation (e.g., hiking) can substantially impact animals if hikers are perceived as risky, leading to costly changes in time allocation and effective habitat loss (Taylor and Knight, 2003; Patten and Burger, 2018). Here, the costs of Type I over-response to humans stem from a mis-assessment of passive recreation activities as risky, suggesting that habituating animals to hikers may help reconcile outdoor recreation with wildlife conservation (Larson et al., 2016). The predictability of recreational activity can facilitate such habituation; red deer (Cervus elaphus) exhibit minimal responses to hikers on wellused trails while strongly avoiding off-trail hikers (Westekemper et al., 2018) and northern cardinals (Cardinalis cardinalis) are less likely to flush when people remain on trails (SmithCastro and Rodewald, 2010). Increasing predictability of human activity by enforcing "stay on trail" rules in protected areas may therefore decrease recreation impacts on wildlife by accelerating habituation (Figure 3). Intentional habituation (e.g., intensive experimental trail use or presentation of human cues along trail 
networks) could be valuable in protected areas transitioning to increased public access (Blumstein, 2016).

\section{Addressing the Costs of Ecotourism-Induced Assessment Mismatches}

Ecotourism activities that provide opportunities to view wildlife at close range can bring in financial resources to support wildlife conservation (Krüger, 2005). However, these efforts come at a cost to wildlife if resulting behavioral modifications have energetic or demographic consequences (Ellenberg, 2017; Geffroy et al., 2017). Deleterious effects of ecotourism are enhanced for wildlife that are large, conspicuous, predictable, and found in open habitats (Green and Higginbottom, 2000). Efforts to examine the fitness consequences of ecotourism-induced riskresponse mismatches in conspicuous wildlife are necessary to meaningfully improve wildlife watching practices. In sea turtles, for example, ecotourism to watch nesting females lay their eggs has particularly strong effects on nesting behaviors, including reduced time spent covering the recently laid eggs (Smith et al., in press). However, behavior changes induced by these guided "turtle watch groups" that follow evidence-based guidelines, such as staying outside of the field of view of the turtle, have not been found to result in measurable consequences for reproductive behaviors including clutch size, hatching success, or emergence success (Johnson et al., 1996; Smith et al., in press). The important disconnect between ecotourism-induced behavior change and reproductive success in nesting sea turtles [and minke whales, (Balaenoptera acutorostrata); Christiansen and Lusseau, 2015] indicates that assessment mismatch doesn't intrinsically lead to individual-level consequences. However, ecotourists that do not comply with turtle-viewing codes of conduct overwhelmingly cause sea turtles to abort their nesting attempts (Waayers et al., 2006). In this case, tools to reduce demographic impacts of sea turtle ecotourism are already being studied and implemented (Smith et al., in press), and simply enforcing conservative codes of conduct should reduce Type I assessment errors made by nesting females exposed to ecotourist groups (Figure 3). In ecotourism systems that do not yet have institutional or established codes of conduct, research on the fitness consequences of behavior change is essential to develop protocols that mitigate the impact of potential assessment mismatches.

\section{Reducing Bycatch in Fisheries}

Fisheries bycatch of non-target species has contributed to the declines of many species of conservation concern (Lewison et al., 2004). Animals that are unable to detect intentionally invisible fishing equipment (detection mismatch) or do not associate equipment with risk (assessment mismatch) can under-respond and face capture at high rates (Werner et al., 2015). Although many attempts to reduce bycatch have been pursued through mechanical innovations (e.g., bycatch reduction devices; Vasapollo et al., 2019), behavioral approaches are being increasingly developed and implemented. Modifications to fishing equipment that better align risk and assessment in non-target animals have been introduced to minimize bycatch
(Gilman, 2011), including introduction of risk cues alongside fishing equipment so that the gear is detected, perceived as risky, and avoided by bycatch species (Southwood et al., 2008; Jordan et al., 2013; Figure 3). Specific sensory tools include acoustic deterrents (Southwood et al., 2008; Waples et al., 2013) olfactory or electrosensory cues (Jordan et al., 2013), LED lights (Bielli et al., 2020), or predator decoys (Bostwick et al., 2014). For species that are not consistently excluded using bycatch reduction devices [e.g., smalleyed round stingray (Urotrygon microphthalmum); Willems et al., 2016], innovations in behavioral deterrents may be necessary to reduce capture. Further study is needed to understand the long-term effectiveness of behavioral bycatch reduction tools, the cost and durability for their large-scale application, and the potential loss of target catch.

\section{CHALLENGES IN UNDERSTANDING ANIMAL PERCEPTION OF RISK}

Despite many examples of apparent risk-response mismatch in wildlife, it is often challenging, if not impossible, for scientific observers to concretely assess perception of risk among freeranging animals (Gaynor et al., 2019). In many instances of risk-response mismatch, it may be the case that animals do correctly detect and assess lethal anthropogenic risk but choose not to respond, perhaps because they perceive other threats (e.g., conspecifics, competitors, starvation, or thermal conditions) to be greater than the risk posed by humans. For instance, female moose with calves show increased use of roadways in Yellowstone National Park, United States, despite the potential risk of vehicle mortality, presumably because moose calf predators (i.e., large carnivores) tend to avoid high human presence around roads (Berger, 2007). Animals may also determine that the benefits associated with human activity outweigh the risks, as in the case of brown bears in Banff National Park, Canada, which are attracted to spilled grain on railway tracks despite risk of train collision (St. Clair et al., 2019). Because human activities often alter many aspects of an animal's environment - including creating heat islands, benefiting synanthropic competitors, and modifying food availability - the context- and state-dependence of animal decision-making may result in an adaptive behavior that appears to researchers to be a risk-response mismatch. Similarly, an animal may perceive relatively low risk from benign human activities, yet it might assess that the cost of responding is minimal and therefore exhibit anti-predator behavior. Complex risk trade-offs undermine the ability of researchers to fully understand the role of animal perception in influencing responses to predation risk, even in predator-prey interactions with a long evolutionary history. The many environmental and ecological changes associated with anthropogenic activities (e.g., resource subsidies, altered competition and predation regimes, and cue inundation) further complicate the assessment of risk perception in animals. Experimental exposure of anthropogenic cues to animals across disturbance and environmental gradients can be used to better tease apart the mechanisms of behavioral responses and to explore the contexts in which risk-response mismatches occur (Smith et al., 2020). 


\section{CONCLUSION}

Human activity has rapidly and dramatically reshaped ecosystems worldwide, and many species have been unable to adapt to the novelty and diversity of both lethal and nonlethal disturbances. Animals cannot always rely on existing sensory mechanisms and decision rules to accurately detect, assess, and respond to lethal and benign anthropogenic stimuli due to the unique nature of human cues. The resulting overresponses to benign stimuli (Type I error) and under-responses to lethal stimuli (Type II error) can be costly, and likely contribute to the outsized lethal and non-lethal effects of humans. Mismatches between anthropogenic risk and animal response may therefore represent an important but often-overlooked pathway linking anthropogenic disturbance to global defaunation and animal declines. Beyond the individual- and population-level consequences discussed here, risk-response mismatch in animals also likely affect species interactions and community-level biodiversity by changing the behavior, density, or distribution of important predators, competitors, or prey (Wilson et al., 2020). Future research is needed to understand the contribution of animal physiology and evolved behavioral strategies to errors in risk response, the processes by which errors scale up to negative consequences at the population level, and which conservation approaches can best alleviate unintended mismatches in risk

\section{REFERENCES}

Amo, L., and López, P. (2006). Nature-based tourism as a form of predation risk affects body condition and health state of Podarcis muralis lizards. Biol. Cons. 131, 402-409. doi: 10.1016/j.biocon.2006.02.015

Arroyo, B., Mougeot, F., and Bretagnolle, V. (2017). Individual variation in behavioural responsiveness to humans leads to differences in breeding success and long-term population phenotypic changes. Ecol. Lett. 20, 317-325. doi: 10.1111/ele.12729

Bateman, P. W., and Fleming, P. A. (2017). Are negative effects of tourist activities on wildlife over-reported? A review of assessment methods and empirical results. Biol. Cons. 211, 10-19. doi: 10.1016/j.biocon.2017.05.003

Beale, C. M., and Monaghan, P. (2004). Behavioural responses to human disturbance: a matter of choice? Anim. Behav. 68, 1065-1069. doi: 10.1016/j. anbehav.2004.07.002

Bejder, L., Samuels, A., Whitehead, H., Finn, H., and Allen, S. (2009). Impact assessment research: use and misuse of habituation, sensitisation and tolerance in describing wildlife responses to anthropogenic stimuli. Mar. Ecol. Prog. Ser. 395, 177-185. doi: 10.3354/meps07979

Berger, J. (2007). Fear, human shields and the redistribution of prey and predators in protected areas. Biol. Lett. 3, 620-623. doi: 10.1098/rsbl.2007.0415

Bernhardt, G. E., Blackwell, B. F., DeVault, T. L., and Kutschbach-Brohl, L. (2010). Fatal injuries to birds from collisions with aircraft reveal anti-predator behaviours: Bird collisions with aircraft. IBIS 152, 830-834. doi: 10.1111/j.1474919X.2010.01043.x

Bielli, A., Alfaro-Shigueto, J., Doherty, P. D., Godley, B. J., Ortiz, C., Pasara, A., et al. (2020). An illuminating idea to reduce bycatch in the Peruvian small-scale gillnet fishery. Biol. Cons. 241:108277. doi: 10.1016/j.biocon.2019.108277

Bird, R. B., and Nimmo, D. (2018). Restore the lost ecological functions of people. Nat. Ecol. Evol. 2, 1050-1052. doi: 10.1038/s41559-018-0576-5

Blumstein, D. T. (2006). The multipredator hypothesis and the evolutionary persistence of antipredator behavior. Ethology 112, 209-217. doi: 10.1111/j. 1439-0310.2006.01209.x

Blumstein, D. T. (2016). Habituation and sensitization: new thoughts about old ideas. Anim. Behav. 120, 255-262. doi: 10.1016/j.anbehav.2016.05.012 response. Our hypotheses regarding the underlying drivers of mismatch can serve as a starting point to addressing these critical questions. By understanding how animals adapt (or fail to adapt) to novel anthropogenic stimuli, either through learning or natural selection, we can better design management interventions to mitigate unintended consequences of human activity and conserve vulnerable species.

\section{AUTHOR CONTRIBUTIONS}

All authors contributed equally to the conception of this work and to the writing, and approved it for publication.

\section{FUNDING}

KG was supported by the Schmidt Science Fellows program, in partnership with the Rhodes Trust. Publication was supported by the UC Santa Barbara Library Open Access Publishing Fund.

\section{ACKNOWLEDGMENTS}

We are very grateful for thoughtful feedback provided by A. Van Scoyoc and E. Ritchie. Figure 3 was kindly illustrated by Z. Beba.

Blumstein, D. T., and Bouskila, A. (1996). Assessment and decision making in animals: A mechanistic model underlying behavioral flexibility can prevent ambiguity. Oikos 77, 569-576. doi: 10.2307/3545948

Blumstein, D. T., Fernández-Juricic, E., Zollner, P. A., and Garity, S. C. (2005). Inter-specific variation in avian responses to human disturbance. J. Appl. Ecol. 42, 943-953. doi: 10.1111/j.1365-2664.2005.01071.x

Blumstein, D. T., Letnic, M., and Moseby, K. E. (2019). In situ predator conditioning of naive prey prior to reintroduction. Phil. Trans. R. Soc. B Biol. Sci. 374:20180058. doi: 10.1098/rstb.2018.0058

Bostwick, A., Higgins, B. M., Landry, A. M., and McCracken, M. L. (2014). Novel use of a shark model to elicit behavioral responses in sea turtles: application to bycatch reduction in commercial fisheries. Chelonian Cons. Biol. 13, 237-246. doi: 10.2744/CCB-1110.1

Bouskila, A., and Blumstein, D. T. (1992). Rules of thumb for predation hazard assessment: predictions from a dynamic model. Am. Nat. 139, 161-176. doi: $10.1086 / 285318$

Bradshaw, C. J., Boutin, S., and Hebert, D. M. (1998). Energetic implications of disturbance caused by petroleum exploration to woodland caribou. Can. J. Zool. 76, 1319-1324. doi: 10.1139/z98-076

Bryce, C. M., Wilmers, C. C., and Williams, T. M. (2017). Energetics and evasion dynamics of large predators and prey: pumas vs. hounds. PeerJ 5:e3701. doi: 10.7717/peerj.3701

Carrete, M., and Tella, J. L. (2013). High individual consistency in fear of humans throughout the adult lifespan of rural and urban burrowing owls. Sci. Rep. 3:3524. doi: $10.1038 /$ srep03524

Carroll, C. (2007). Interacting effects of climate change, landscape conversion, and harvest on carnivore populations at the range margin: marten and lynx in the Northern Appalachians. Cons. Biol. 21, 1092-1104. doi: 10.1111/j.1523-1739. 2007.00719.x

Carthey, A. J. R., and Blumstein, D. T. (2017). Predicting predator recognition in a changing world. Trends Ecol. Evol. 33, 106-115. doi: 10.1016/j.tree.2017. 10.009

Cherry, M. J., Morgan, K. E., Rutledge, B. T., Conner, L. M., and Warren, R. J. (2016). Can coyote predation risk induce reproduction suppression in whitetailed deer? Ecosphere 7:e01481. doi: 10.1002/ecs2.1481 
Christiansen, F., and Lusseau, D. (2015). Linking behavior to vital rates to measure the effects of non-lethal disturbance on wildlife. Cons. Lett. 8, 424-431. doi: $10.1111 /$ conl. 12166

Cooper, W. E., Pyron, R. A., and Garland, T. (2014). Island tameness: living on islands reduces flight initiation distance. Proc. R. Soc. B: Biol. Sci. 281:20133019. doi: 10.1098/rspb.2013.3019

Cox, J. G., and Lima, S. L. (2006). Naiveté and an aquatic-terrestrial dichotomy in the effects of introduced predators. Trends Ecol. Evol. 21, 674-680. doi: 10.1016/j.tree.2006.07.011

Crane, A. L., Brown, G. E., Chivers, D. P., and Ferrari, M. C. O. (2019). An ecological framework of neophobia: from cells to organisms to populations. Biol. Rev. 95, 218-231. doi: 10.1111/brv.12560

Creel, S., Fox, J. E., Hardy, A., Sands, J., Garrott, B., and Peterson, R. O. (2002). Snowmobile activity and glucocorticoid stress responses in wolves and elk. Cons. Biol. 16, 809-814. doi: 10.1046/j.1523-1739.2002.00554.x

Cromsigt, J. P. G. M., Kuijper, D. J. P., Adam, M., Beschta, R. L., Churski, M., Eycott, A. G., et al. (2013). Hunting for fear: innovating management of human-wildlife conflicts. J. Appl. Ecol. 50, 544-549. doi: 10.1111/1365-2664. 12076

Darimont, C. T., Fox, C. H., Bryan, H. M., and Reimchen, T. E. (2015). The unique ecology of human predators. Science 349, 858-860. doi: 10.1126/science. aac4249

DeVault, T. L., Blackwell, B. F., Seamans, T. W., Lima, S. L., and Fernández-Juricic, E. (2015). Speed kills: ineffective avian escape responses to oncoming vehicles. Proc. R. Soc. B Biol. Sci. 282:20142188. doi: 10.1098/rspb.2014.2188

DeVault, T. L., Seamans, T. W., Blackwell, B. F., Lima, S. L., Martinez, M. A., and Fernández-Juricic, E. (2016). Can experience reduce collisions between birds and vehicles? J. Zool. 301, 17-22. doi: 10.1111/jzo.12385

Dirzo, R., Young, H. S., Galetti, M., Ceballos, G., Isaac, N. J. B., and Collen, B. (2014). Defaunation in the Anthropocene. Science 345, 401-406. doi: 10.1126/ science. 1251817

Ditmer, M. A., Rettler, S. J., Fieberg, J. R., Iaizzo, P. A., Laske, T. G., Noyce, K. V., et al. (2018). American black bears perceive the risks of crossing roads. Behav. Ecol. 29, 667-675. doi: 10.1093/beheco/ary020

Dominoni, D. M., Halfwerk, W., Baird, E., Buxton, R. T., Fernández-Juricic, E., Fristrup, K. M., et al. (2020). Why conservation biology can benefit from sensory ecology. Nat. Ecol. Evol. 4, 502-511. doi:10.1038/s41559-0201135-4

Donadio, E., and Buskirk, S. W. (2006). Flight behavior in guanacos and vicuñas in areas with and without poaching in western Argentina. Biol. Cons. 127, 139-145. doi: 10.1016/j.biocon.2005.08.004

Dwinnell, S. P. H., Sawyer, H., Randall, J. E., Beck, J. L., Forbey, J. S., Fralick, G. L., et al. (2019). Where to forage when afraid: Does perceived risk impair use of the foodscape? Ecol. App. 29, 20-16. doi: 10.1002/eap.1972

Ehlman, S. M., Trimmer, P. C., and Sih, A. (2019). Prey responses to exotic predators: effects of old risks and new cues. Am. Nat. 193, 575-587. doi: 10. $1086 / 702252$

Ellenberg, U. (2017). "Impacts of Penguin Tourism," in Ecotourism's Promise and Peril, eds D. Blumstein, B. Geffroy, D. Samia, and E. Bessa (Cham: Springer), 117-132. doi: 10.1007/978-3-319-58331-0_8

Fardell, L. L., Pavey, C. R., and Dickman, C. R. (2020). Fear and stressing in predator-prey ecology: considering the twin stressors of predators and people on mammals. PeerJ 8:e9104. doi: 10.7717/peerj.9104

Fernández-Juricic, E., Sallent, A., and Sanz, R. (2003). Testing the risk-disturbance hypothesis in a fragmented landscape: nonlinear responses of house sparrows to humans. Condor 105, 316-326. doi: 10.1093/condor/105.2.316

Ferrari, M. C. O., Crane, A. L., Brown, G. E., and Chivers, D. P. (2015). Getting ready for invasions: can background level of risk predict the ability of naïve prey to survive novel predators? Sci. Rep. 5:8309. doi: 10.1038/srep08309

Fisher, H. S., Wong, B. B. M., and Rosenthal, G. G. (2006). Alteration of the chemical environment disrupts communication in a freshwater fish. Proc. $R$. Soc. B Biol. Sci. 273, 1187-1193. doi: 10.1098/rspb.2005.3406

French, S. S., González-Suárez, M., Young, J. K., Durham, S., and Gerber, L. R. (2011). Human disturbance influences reproductive success and growth rate in California sea lions (Zalophus californianus). PLoS One 6, 17686-17688e. doi: 10.1371/journal.pone.0017686

Frid, A., and Dill, L. M. (2002). Human-caused disturbance stimuli as a form of predation risk. Cons. Ecol. 6, 1-11. doi: 10.5751/ES-00404-060111
Gaynor, K. M., Brown, J. S., Middleton, A. D., Power, M. E., and Brashares, J. S. (2019). Landscapes of fear: spatial patterns of risk perception and response. Trends Ecol. Evol. 34, 355-368. doi: 10.1016/j.tree.2019.01.004

Gaynor, K. M., Hojnowski, C. E., Carter, N. H., and Brashares, J. S. (2018). The influence of human disturbance on wildlife nocturnality. Science 360, 1232-1235. doi: 10.1126/science.aar7121

Geffroy, B., Sadoul, B., and Ellenberg, U. (2017). "Physiological and Behavioral Consequences of Human Visitation," in Ecotourism's Promise and Peril, eds D. Blumstein, B. Geffroy, D. Samia, and E. Bessa (Cham: Springer), 9-27. doi: 10.1007/978-3-319-58331-0_2

Geffroy, B., Samia, D. S. M., Bessa, E., and Blumstein, D. T. (2015). How naturebased tourism might increase prey vulnerability to predators. Trends Ecol. Evol. 30, 755-765. doi: 10.1016/j.tree.2015.09.010

Gilman, E. L. (2011). Bycatch governance and best practice mitigation technology in global tuna fisheries. Mar. Policy 35, 590-609. doi: 10.1016/j.marpol.2011. 01.021

Green, R. J., and Higginbottom, K. (2000). The effects of non-consumptive wildlife tourism on free-ranging wildlife: a review. Pacific Cons. Biol. 6:183. doi: 10.1071/ PC000183

Griffin, A. S. (2004). Social learning about predators: a review and prospectus. Anim. Learning Behav. 32, 131-140. doi: 10.3758/BF03196014

Guiden, P. W., Bartel, S. L., Byer, N. W., Shipley, A. A., and Orrock, J. L. (2019). Predator-prey interactions in the Anthropocene: reconciling multiple aspects of novelty. Trends Ecol. Evol. 33, 616-627. doi: 10.1016/j.tree.2019. 02.017

Heinemeyer, K., Squires, J., Hebblewhite, M., O’Keefe, J. J., Holbrook, J. D., and Copeland, J. (2019). Wolverines in winter: indirect habitat loss and functional responses to backcountry recreation. Ecosphere 10, 2611-2623e. doi: 10.1002/ ecs 2.2611

Horn, J. W., Arnett, E. B., and Kunz, T. H. (2008). Behavioral responses of bats to operating wind turbines. J. Wildl. Manage. 72, 123-132. doi: 10.2193/2006-465

Johnson, D. D. P., Blumstein, D. T., Fowler, J. H., and Haselton, M. G. (2013). The evolution of error: error management, cognitive constraints, and adaptive decision-making biases. Trends Ecol. Evol. 28, 474-481. doi: 10.1016/j.tree.2013. 05.014

Johnson, H. E., Lewis, D. L., and Breck, S. W. (2020). Individual and population fitness consequences associated with large carnivore use of residential development. Ecosphere 11:e03098. doi: 10.1002/ecs2.3098

Johnson, S. A., Bjorndal, K. A., and Bolten, A. B. (1996). Effects of organized turtle watches on loggerhead (Caretta caretta) nesting behavior and hatchling production in Florida. Cons. Biol. 10, 570-577. doi: 10.1046/j.1523-1739.1996. 10020570.x

Jordan, L. K., Mandelman, J. W., McComb, D. M., Fordham, S. V., Carlson, J. K., and Werner, T. B. (2013). Linking sensory biology and fisheries bycatch reduction in elasmobranch fishes: a review with new directions for research. Cons. Physiol. 1:cot002. doi: 10.1093/conphys/cot002

Kays, R., Parsons, A. W., Baker, M. C., Kalies, E. L., Forrester, T., Costello, R., et al. (2017). Does hunting or hiking affect wildlife communities in protected areas? J. Appl. Ecol. 54, 242-252. doi: 10.1111/1365-2664.12700

Kerley, L. L., Goodrich, J. M., and Miquelle, D. G. (2002). Effects of roads and human disturbance on Amur tigers. Cons. Biol. 16, 97-108. doi: 10.1046/j.15231739.2002.99290.x

Krüger, O. (2005). The role of ecotourism in conservation: panacea or Pandora's box? Biodiv. Cons. 14, 579-600. doi: 10.1007/s10531-004-3917-4

Larson, C. L., Reed, S. E., Merenlender, A. M., and Crooks, K. R. (2016). Effects of recreation on animals revealed as widespread through a global systematic review. PLoS One 11:e0167259. doi: 10.1371/journal.pone.01 67259

Lesmerises, F., Déry, F., Johnson, C. J., and St-Laurent, M. H. (2018). Spatiotemporal response of mountain caribou to the intensity of backcountry skiing. Biol. Cons. 217, 149-156. doi: 10.1016/j.biocon.2017. 10.030

Lewison, R. L., Crowder, L. B., Read, A. J., and Freeman, S. A. (2004). Understanding impacts of fisheries bycatch on marine megafauna. Trends Ecol. Evol. 19, 598-604. doi: 10.1016/j.tree.2004.09.004

Lima, S. L., and Bednekoff, P. A. (1999). Temporal variation in danger drives antipredator behavior: the predation risk allocation hypothesis. Am. Nat. 153, 649-659. doi: 10.1086/303202 
Loss, S. R., Will, T., and Marra, P. P. (2012). Direct human-caused mortality of birds: improving quantification of magnitude and assessment of population impact. Front. Ecol. Environ. 10, 357-364. doi: 10.1890/110251

Loss, S. R., Will, T., and Marra, P. P. (2015). Direct mortality of birds from anthropogenic causes. Ann. Rev. Ecol. Evol. Syst. 46, 99-120. doi: 10.1146/ annurev-ecolsys-112414-054133

Loveridge, A. J., Valeix, M., Elliot, N. B., and Macdonald, D. W. (2017). The landscape of anthropogenic mortality: how African lions respond to spatial variation in risk. J. Appl. Ecol. 54, 815-825. doi: 10.1111/1365-2664.12794

Mandelman, J. W., Cooper, P. W., Werner, T. B., and Lagueux, K. M. (2008). Shark bycatch and depredation in the U.S. Atlantic pelagic longline fishery. Rev. Fish Biol. Fisher. 18, 427-442. doi: 10.1007/s11160-008-9084-z

Mazerolle, M. J., Huot, M., and Gravel, M. (2005). Behavior of amphibians on the road in relation to car traffic. Herpetologica 61, 380-388. doi: 10.1655/04-79.1

Mccardle, L. D., and Fontenot, C. L. (2016). The influence of thermal biology on road mortality risk in snakes. J. Thermal Biol. 56, 39-49. doi: 10.1016/j.jtherbio. 2015.12.004

McClenachan, L., and Cooper, A. B. (2008). Extinction rate, historical population structure and ecological role of the Caribbean monk seal. Proc. R. Soc. B Biol. Sci. 275, 1351-1358. doi: 10.1098/rspb.2007.1757

McClung, M. R., Seddon, P. J., Massaro, M., and Setiawan, A. N. (2004). Naturebased tourism impacts on yellow-eyed penguins Megadyptes antipodes: does unregulated visitor access affect fledging weight and juvenile survival? Biol. Cons. 119, 279-285. doi: 10.1016/j.biocon.2003.11.012

McComb, K., Shannon, G., Sayialel, K. N., and Moss, C. (2014). Elephants can determine ethnicity, gender, and age from acoustic cues in human voices. Proc. Natl. Acad. Sci. U S A. 111, 5433-5438. doi: 10.1073/pnas.1321543111

Meekan, M. G., McCormick, M. I., Simpson, S. D., Chivers, D. P., and Ferrari, M. C. O. (2018). Never off the hook-how fishing subverts predator-prey relationships in marine teleosts. Front. Ecol. Evol. 6:157. doi: 10.3389/fevo.2018. 00157

Merenlender, A. M., Reed, S. E., and Heise, K. L. (2009). Exurban development influences woodland bird composition. Landsc. Urban Plan. 92, 255-263. doi: 10.1016/j.landurbplan.2009.05.004

Møller, A. P., Samia, D. S. M., Weston, M. A., Guay, P. J., and Blumstein, D. T. (2014). American exceptionalism: population trends and flight initiation distances in birds from three continents. PLoS One 9:e107883. doi: 10.1371/ journal.pone.0107883

Müllner, A., Linsenmair, K. E., and Wikelski, M. (2004). Exposure to ecotourism reduces survival and affects stress response in hoatzin chicks (Opisthocomus hoazin). Biol. Cons. 118, 549-558. doi: 10.1016/j.biocon.2003.10.003

Nickel, B. A., Suraci, J. P., Allen, M. L., and Wilmers, C. C. (2020). Human presence and human footprint have non-equivalent effects on wildlife spatiotemporal habitat use. Biol. Cons. 241:108383. doi: 10.1016/j.biocon.2019.108383

Northrup, J. M., Anderson, C. R. Jr., and Wittemyer, G. (2015). Quantifying spatial habitat loss from hydrocarbon development through assessing habitat selection patterns of mule deer. Glob. Change Biol. 21, 3961-3970. doi: 10.1111/gcb. 13037

Nyhus, P. J. (2016). Human-wildlife conflict and coexistence. Annu. Rev. Environ. Res. 41, 1-29. doi: 10.1146/annurev-environ-110615-085634

Oriol-Cotterill, A., Valeix, M., Frank, L. G., Riginos, C., and Macdonald, D. W. (2015). Landscapes of Coexistence for terrestrial carnivores: the ecological consequences of being downgraded from ultimate to penultimate predator by humans. Oikos 124, 1263-1273. doi: 10.1111/oik.02224

Orrock, J. L., Sih, A., Ferrari, M. C. O., Karban, R., Preisser, E. L., Sheriff, M. J., et al. (2015). Error management in plant allocation to herbivore defense. Trends Ecol. Evol. 30, 441-445. doi: 10.1016/j.tree.2015.06.005

Owen, M. A., Swaisgood, R. R., and Blumstein, D. T. (2017). Contextual influences on animal decision-making: Significance for behavior-based wildlife conservation and management. Integrat. Zool. 12, 32-48. doi: 10.1111/17494877.12235

Patten, M. A., and Burger, J. C. (2018). Reserves as double-edged swordAvoidance behavior in an urban-adjacent wildland. Biol. Cons. 218, 233-239. doi: 10.1016/j.biocon.2017.12.033

Peacor, S. D., Pangle, K. L., Schiesari, L., and Werner, E. E. (2011). Scaling-up anti-predator phenotypic responses of prey: impacts over multiple generations in a complex aquatic community. Proc. R. Soc. B Biol. Sci. 279, 122-128. doi: $10.1098 /$ rspb.2011.0606
Peckarsky, B. L., Cowan, C. A., Penton, M. A., and Anderson, C. (1993). Sublethal consequences of stream-dwelling predatory stoneflies on mayfly growth and fecundity. Ecology 74, 1836-1846. doi: 10.2307/1939941

Petracca, L. S., Frair, J. L., Bastille-Rousseau, G., Hunt, J. E., Macdonald, D., Sibanda, L., et al. (2019). The effectiveness of hazing African lions as a conflict mitigation tool: implications for carnivore management. Ecosphere 10:e02967. doi: $10.1002 /$ ecs 2.2967

Ripple, W. J., Abernethy, K., Betts, M. G., Chapron, G., Dirzo, R., Galetti, M., et al. (2016). Bushmeat hunting and extinction risk to the world's mammals. R. Soc. Open Sci. 3, 160498-160416. doi: 10.1098/rsos.160498

Robertson, B. A., Rehage, J. S., and Sih, A. (2013). Ecological novelty and the emergence of evolutionary traps. Trends Ecol. Evol. 28, 552-560. doi: 10.1016/j. tree.2013.04.004

Rogala, J. K., Hebblewhite, M., and Whittington, J. (2011). Human activity differentially redistributes large mammals in the Canadian Rockies National Parks. Ecol. Soc. 16:art16. doi: 10.5751/ES-04251-160316

Rösner, S., Mussard-Forster, E., Lorenc, T., and Müller, J. (2014). Recreation shapes a "landscape of fear" for a threatened forest bird species in Central Europe. Landscape Ecol. 29, 55-66. doi: 10.1007/s10980-013-9964-z

Samia, D. S. M., Nakagawa, S., Nomura, F., Rangel, T. F., and Blumstein, D. T. (2015). Increased tolerance to humans among disturbed wildlife. Nat. Comm. 6:8877. doi: 10.1038/ncomms9877

Saul, W. C., and Jeschke, J. M. (2015). Eco-evolutionary experience in novel species interactions. Ecol. Lett. 18, 236-245. doi: 10.1111/ele.12408

Savoca, M. S., Tyson, C. W., McGill, M., and Slager, C. J. (2017). Odours from marine plastic debris induce food search behaviours in a forage fish. Proc. $R$. Soc. B Biol. Sci. 284, 20171000-20171003. doi: 10.1098/rspb.2017.1000

Sawyer, H., Korfanta, N. M., Nielson, R. M., Monteith, K. L., and Strickland, D. (2017). Mule deer and energy development-Long-term trends of habituation and abundance. Glob. Change Biol. 121,3-9. doi: 10.1111/gcb.13711

Serieys, L. E. K., Armenta, T. C., Moriarty, J. G., Boydston, E. E., Lyren, L. M., Poppenga, R. H., et al. (2015). Anticoagulant rodenticides in urban bobcats: exposure, risk factors and potential effects based on a 16-year study. Ecotoxicology 24, 844-862. doi: 10.1007/s10646-015-1429-5

Sih, A. (2013). Understanding variation in behavioural responses to humaninduced rapid environmental change: a conceptual overview. Anim. Behav. 85, 1077-1088. doi: 10.1016/j.anbehav.2013.02.017

Sih, A., Bolnick, D. I., Luttbeg, B., Orrock, J. L., Peacor, S. D., Pintor, L. M., et al. (2010). Predator-prey naïveté, antipredator behavior, and the ecology of predator invasions. Oikos 119, 610-621. doi: 10.1111/j.1600-0706.2009.18039.x

Sih, A., Ferrari, M. C. O., and Harris, D. J. (2011). Evolution and behavioural responses to human-induced rapid environmental change. Evol. App. 4, 367387. doi: 10.1111/j.1752-4571.2010.00166.x

Smallwood, K. S. (2013). Comparing bird and bat fatality-rate estimates among North American wind-energy projects. Wildl. Soc. Bull. 37, 19-33. doi: 10.1002/ wsb. 260

Smith, J. A., Suraci, J. P., Clinchy, M., Crawford, A., Roberts, D., Zanette, L. Y., et al. (2017). Fear of the human "super predator" reduces feeding time in large carnivores. Proc. R. Soc. B Biol. Sci. 284, 20170433-20170435. doi: 10.1098/rspb. 2017.0433

Smith, J. A., Suraci, J. P., Hunter, J. S., Gaynor, K. M., Keller, C. B., Palmer, M. S., et al. (2020). Zooming in on mechanistic predator-prey ecology: integrating camera traps with experimental methods to reveal the drivers of ecological interactions. J. Anim. Ecol. 89, 1997-2012. doi: 10.1111/1365-2656.13264

Smith, J. A., Wang, Y., and Wilmers, C. C. (2015). Top carnivores increase their kill rates on prey as a response to human-induced fear. Proc. R. Soc. B: Biol. Sci. 282, 20142711-20142711. doi: 10.1098/rspb.2014.2711

Smith, J.R., Lindborg, R. J., Hernandez, V., Abney, E.A. and Witherington, B. E. (in press). Using behavior indices and vital rates to determine the conservation impact of wildlife tourism: Guided sea turtle watch programs in Florida. Glob. Ecol. Conserv.

Smith-Castro, J. R., and Rodewald, A. D. (2010). Behavioral responses of nesting birds to human disturbance along recreational trails. J. Field Ornith. 81, 130138. doi: 10.1111/j.1557-9263.2010.00270.x

Southwood, A., Fritsches, K., Brill, R., and Swimmer, Y. (2008). Sound, chemical, and light detection in sea turtles and pelagic fishes: sensory-based approaches to bycatch reduction in longline fisheries. Endanger. Species Res. 5, 225-238. doi: 10.3354/esr00097 
St. Clair, C. C., Backs, J., Friesen, A., Gangadharan, A., Gilhooly, P., Murray, M., et al. (2019). Animal learning may contribute to both problems and solutions for wildlife-train collisions. Phil. Trans. Roy. Soc. B Biol. Sci. 374:20180050. doi: $10.1098 /$ rstb.2018.0050

Stankowich, T. (2008). Ungulate flight responses to human disturbance: a review and meta-analysis. Biol. Cons. 141, 2159-2173. doi: 10.1016/j.biocon.2008. 06.026

Stockwell, C. A., Bateman, G. C., and Berger, J. (1991). Conflicts in national parks: A case study of helicopters and bighorn sheep time budgets at the Grand Canyon. Biol. Cons. 56, 317-328. doi: 10.1016/0006-3207(91)90064-G

Suraci, J. P., Clinchy, M., Zanette, L. Y., and Wilmers, C. C. (2019). Fear of humans as apex predators has landscape-scale impacts from mountain lions to mice. Ecol. Lett. 22, 1578-1586. doi: 10.1111/ele.13344

Suuronen, P., Lehtonen, E., and Wallace, J. (1997). Avoidance and escape behaviour by herring encountering midwater trawls. Fish. Res. 29, 13-24. doi: 10.1016/ S0165-7836(96)00523-1

Taylor, A. R., and Knight, R. L. (2003). Behavioral responses of wildlife to human activity: terminology and methods. Wildl. Soc. Bull. 31, 1263-1271.

Thapa, T. B. (2015). Human Caused Mortality in the Leopard (Panthera pardus) Population of Nepal. J. Inst. Sci. Tech. 19, 155-150. doi: 10.3126/jist.v19i1.13842

Thouless, C. R., Grainger, J. G., Shobrak, M., and Habibi, K. (1991). Conservation status of gazelles in Saudi Arabia. Biol. Cons. 58, 85-98. doi: 10.1016/00063207(91)90046-C

Thurfjell, H., Ciuti, S., and Boyce, M. S. (2017). Learning from the mistakes of others: How female elk (Cervus elaphus) adjust behaviour with age to avoid hunters. PLoS One 12, 178082. doi: 10.1371/journal.pone.0178082

Tran, D. S. C., Langel, K. A., Thomas, M. J., and Blumstein, D. T. (2016). Spearfishing-induced behavioral changes of an unharvested species inside and outside a marine protected area. Curr. Zool. 62, 39-44. doi: 10.1093/cz/zov006

Trimmer, P. C., Ehlman, S. M., and Sih, A. (2017b). Predicting behavioural responses to novel organisms: state-dependent detection theory. Proc. R. Soc. B Biol. Sci. 284, 20162108-20162109. doi: 10.1098/rspb.2016.2108

Trimmer, P. C., Ehlman, S. M., McNamara, J. M., and Sih, A. (2017a). The erroneous signals of detection theory. Proc. R. Soc. B Biol. Sci. 284, $20171852-$ 20171856. doi: 10.1098/rspb.2017.1852

Van Heezik, Y., Seddon, P. J., and Maloney, R. F. (1999). Helping reintroduced houbara bustards avoid predation: effective anti-predator training and the predictive value of pre-release behaviour. Anim. Cons. 2, 155-163. doi: 10.1111/ j.1469-1795.1999.tb00061.x

Vasapollo, C., Virgili, M., Petetta, A., Bargione, G., Sala, A., and Lucchetti, A. (2019). Bottom trawl catch comparison in the Mediterranean Sea: Flexible Turtle Excluder Device (TED) vs traditional gear. PLoS One 14:e216023. doi: 10.1371/journal.pone.0216023

Venter, O., Sanderson, E. W., Magrach, A., Allan, J. R., Beher, J., Jones, K. R., et al. (2016). Sixteen years of change in the global terrestrial human footprint and implications for biodiversity conservation. Nat. Comm. 7, 1-11. doi: 10.1038/ ncomms 12558

Waayers, D., Newsome, D., and Lee, D. (2006). Observations of non-compliance behaviour by tourists to a voluntary code of conduct: A pilot study of turtle tourism in the Exmouth Region, Western Australia. J. Ecotour. 5, 211-222. doi: $10.2167 /$ joe 100.0
Waples, D. M., Thorne, L. H., Hodge, L. E. W., Burke, E. K., Urian, K. W., and Read, A. J. (2013). A field test of acoustic deterrent devices used to reduce interactions between bottlenose dolphins and a coastal gillnet fishery. Biol. Cons. 157, 163-171. doi: 10.1016/j.biocon.2012.07.012

Wat, K. K. Y., Herath, A. P. H. M., Rus, A. I., Banks, P. B., and Mcarthur, C. (2020). Space use by animals on the urban fringe: interactive effects of sex and personality. Behav. Ecol. 31, 330-339. doi: 10.1093/beheco/arz194

Welton, N. J., McNamara, J. M., and Houston, A. I. (2003). Assessing predation risk: optimal behaviour and rules of thumb. Theor. Pop. Biol. 64, 417-430. doi: 10.1016/S0040-5809(03)00097-2

Werner, T. B., Northridge, S., Press, K. M., and Young, N. (2015). Mitigating bycatch and depredation of marine mammals in longline fisheries. ICES J. Mar. Sci. 72, 1576-1586. doi: 10.1093/icesjms/fsv092

Westekemper, K., Reinecke, H., Signer, J., Meiner, M., Herzog, S., and Balkenhol, N. (2018). Stay on trails effects of human recreation on the spatiotemporal behavior of red deer Cervus elaphus in a German national park. Wildl. Biol. 2018:wlb.00403. doi: 10.2981/wlb.00403

Weston, M. A., McLeod, E. M., Blumstein, D. T. and Guay, P. J. (2012). A review of flight-initiation distances and their application to managing disturbance to Australian birds. Emu 112, 269-286. doi: 10.1071/mu12026

Willems, T., Depestele, J., Backer, A. D., and Hostens, K. (2016). Ray bycatch in a tropical shrimp fishery: do Bycatch Reduction Devices and Turtle Excluder Devices effectively exclude rays? Fish. Res. 175, 35-42. doi: 10.1016/j.fishres. 2015.11.009

Williams, T. M., Blackwell, S. B., Richter, B., Sinding, M. S., and Heide-Jørgensen, M. P. (2017). Paradoxical escape responses by narwhals (Monodon monoceros). Science 358, 1328-1331. doi: 10.1126/science.aao2740

Wilson, M. W., Ridlon, A. D., Gaynor, K. M., Gaines, S. D., and Stier, A. C. (2020). Ecological impacts of human-induced animal behaviour change. Ecol. Lett. 23, 1522-1536. doi: 10.1111/ele.13571

Wisdom, M. J., Preisler, H. K., Naylor, L. M., Anthony, R. G., Johnson, B. K., and Rowland, M. M. (2018). Elk responses to trail-based recreation on public forests. Forest Ecol. Mgmt. 411, 223-233. doi: 10.1016/j.foreco.2018.01.032

Young, J. K., Hammill, E., and Breck, S. W. (2019). Interactions with humans shape coyote responses to hazing. Sci. Rep. 9:20046. doi: 10.1038/s41598-019-56 524-6

Zbyryt, A., Bubnicki, J. K., Kuijper, D., Dehnhard, M., Churski, M., and Schmidt, K. (2017). Do wild ungulates experience higher stress with humans than with large carnivores? Behav. Ecol. 29, 19-30. doi: 10.1093/beheco/ $\operatorname{arx} 142$

Conflict of Interest: The authors declare that the research was conducted in the absence of any commercial or financial relationships that could be construed as a potential conflict of interest.

Copyright (c) 2021 Smith, Gaynor and Suraci. This is an open-access article distributed under the terms of the Creative Commons Attribution License (CC BY). The use, distribution or reproduction in other forums is permitted, provided the original author(s) and the copyright owner(s) are credited and that the original publication in this journal is cited, in accordance with accepted academic practice. No use, distribution or reproduction is permitted which does not comply with these terms. 